\title{
UNIVERSIDADE PÚBLICA ESTATAL: ENTRE O PÚBLICO E O PRIVADO/MERCANTIL*
}

\author{
VALDEMAR SGUiSSARDi ${ }^{* *}$
}

Aquele que recebe uma idéia de mim, recebe uma lição própria sem diminuir a minha; assim como aquele que acende sua vela na minha, recebe luz sem me obscurecer.

(Thomas Jefferson, apud Stiglitz, 1999)

\begin{abstract}
RESUMO: Com este artigo pretende-se contribuir para o debate em torno do dilema que enfrentariam hoje as universidades estatais públicas, tanto nos países centrais como nos da periferia e semiperiferia, isto é, diante dos constrangimentos econômico-financeiros e da nova concepção de economia, de Estado e de direitos ou serviços públicos, verem-se identificadas como bem público ou privado/mercantil. Visase a mostrar que é a multissecular identidade universitária que está em jogo. Para tanto, partindo de fenômenos bastante universais como os da extraordinária expansão do setor privado, em especial privado/mercantil, da redução dos investimentos estatais nas universidades públicas e do trânsito da autonomia para a heteronomia universitária, problematizam-se o tema do conhecimento - provido pelo ensino superior - como bem público ou bem privado, as principais teses envolvidas nesta questão e suas decorrências para a identidade universitária. O material empírico do estudo constitui-se de alguns documentos do Banco Mundial, da OMC e da UNESCO, assim como de dados sobre financiamento e expansão da educação superior no Brasil, entre outros. À guisa de conclusão, e de modo sucinto, são examinados alguns novos ou renovados traços e marcas da universi-
\end{abstract}

* Texto, originalmente mais amplo, apresentado na Sessão 4 "O conhecimento como bem público - Necessidade de proteger a universidade pública" da $1^{\text {a Conferencia Regional }}$ Latinoamericana del Foro UNESCO sobre Educación Superior, Investigación y Gestión, Porto Alegre (RS), Brasil, UFRGS e ILEA, de $1^{\circ}$ a 3 de setembro de 2004.

** Professor titular aposentado da Universidade Federal de São Carlos (UFSCAR) e titular da Faculdade de Ciências Humanas da Universidade Metodista de Piracicaba (UnIMEP). E-mail: vs@merconet.com.br

Educ. Soc., Campinas, vol. 26, n. 90, p. 191-222, Jan./Abr. 2005

Disponível em <http://www.cedes.unicamp.br> 
dade de "modelo anglo-saxão", modelo que parece tornar-se hegemônico em países do Norte e do Sul.

Palavras-chave: Conhecimento como bem público. Universidade pública estatal. Modelo anglo-saxônico. Público x privado/mercantil.

\section{STATE PUBLIC UNIVERSITY: \\ BETWEEN THE PUBLIC AND THE PRIVATE/MERCANTILE}

ABSTRACT: With this article we intend to contribute to the debate on the dilemma the state public universities would face nowadays, both in the central countries and in those countries of the periphery and semi-periphery, that is, before the economic-financial constraints and the new conception of the economy of state and rights or public services. The state public univerties see themselves identified with knowledge as public good or private/mercantile. We aim to show that the identity of the classical university is at stake. For this purpose, considering the very universal phenomenon like the extraordinary expansion of the private sector, specially the private/ mercantile, the reduction of the state investments in the public universities, and the transit from the autonomic to the heteronomic university the theme of knowledge problematizes - due to the higher education - as a public or private good, the main theses involved in this question, and their consequences to the university identity. The empirical material of the study is constituted by some documents from the World Bank, WTO (World Trade Organization) and UNESCO (United Nations Educational, Scientific and Cultural Organization), as well as data about financing and expansion of the higher education in Brazil, among others. By way of conclusion and in a succinct way, some new or renewed feature and marks of the Anglo-Saxon model, model that seem to be hegemonic in countries from North and South, are examined.

Key words: Knowledge as public good. State public university. Anglo-Saxon model. Public x private/mercantile.

\section{Introdução}

crise do Estado do Bem-Estar e do Estado Desenvolvimentis-
ta, tanto nos países centrais como nos da periferia, marca o
início do talvez mais crucial dilema para a universidade esta- 
reitos ou serviços públicos, ver-se identificada como bem público ou privado/mercantil. É a multissecular identidade universitária que está em jogo. Em países como a Inglaterra, onde as universidades não são estatais, nem públicas stricto sensu, mas registered charities (privadas filantrópicas ou comunitárias), o desafio teria adquirido coloração distinta e aparentemente menos dramática que nos países de mais acentuada tradição republicana, como é o caso da maioria dos países europeus e de alguns da periferia ou semiperiferia do mundo globalizado.

Um simples olhar panorâmico sobre a expansão quantitativa de instituiçôes privadas, notadamente com fins lucrativos (for profit), e das matrículas nessas instituições, assim como sobre a lenta mas firme redução dos investimentos estatais nas universidades públicas, com relação ao PIB, de uma amostra aleatória de países ricos e pobres, fornecerá provas contundentes de que a universidade e, por extensão, a educação superior estão passando por profundas mudanças, de que esse dilema - público ou privado/mercantil - ocupa lugar central.

No caso do Brasil, a multiplicação das instituições de ensino superior privadas, em especial com fins lucrativos, ${ }^{1}$ foi extraordinária nos anos recentes, elevando-se seu número a cerca de $90 \%$ do total. As matrículas em instituições privadas já beiram os $80 \%$, com evidente potencial de crescimento. Em contrapartida, mais de $90 \%$ da pesquisa produzida no país - mormente a básica -, mais de $80 \%$ dos mestres e $90 \%$ dos doutores titulados são frutos do investimento público e da atividade científico-acadêmica das universidades públicas (federais e estaduais, entre estas se destacando as estaduais paulistas). ${ }^{2}$

As discussões teóricas sobre se o conhecimento provido mediante o ensino, em especial o de nível superior, é um bem público ou privado ocupam espaço cada dia maior na produção documental dos organismos multilaterais financeiros (BM, BID, OMC) e educacionais (UNESCO), assim como nas linhas e entrelinhas dos discursos governamentais nacionais ou multinacionais (OCDE, UE, NAFTA). Em grande medida esse debate se tem atrelado em especial ao desenvolvimento de teorias econômicas neoclássicas do "capital humano" e do "capital social". ${ }^{3}$

É oportuno enfatizar que essas discussões somente se aceleram a partir do momento em que se impóem as orientaçóes do ajuste 
neoliberal das economias nacionais no final dos anos de 1970, durante os anos de 1980 e 1990, e neste início de século. Destaque-se que elas envolvem "teses" que se têm constituído em arma essencial de convencimento da opinião pública para fazê-la aceitar a redução dos gastos públicos com os direitos da cidadania, hoje considerados em geral serviços públicos não exclusivos do Estado.(BRASIL, MARE, 1995) É necessário observar que essas teses adquirem a cada dia maior relevância após a disseminação das recomendações do Consenso de Washington.

Nas páginas que seguem serão expostas algumas considerações acerca do debate ensino superior como bem público ou como bem privado, e suas principais teses, tendo como material empírico alguns documentos do Banco Mundial, da OMC e da UNESCO; rápidas reflexões sobre a contraposição estatal/público versus privado/mercantil; alguns dados e fatos que demonstram como no Brasil se seguiu bastante à risca, em especial, na educação superior pública federal, a orientação determinada pelas teses hegemônicas desse debate; finalmente, à guisa de conclusão e de modo sucinto, alguns novos ou renovados traços e marcas da universidade de "modelo anglo-saxão", que parece tornar-se hegemônico tanto nos países centrais como nos da periferia e semiperiferia.

\section{O ensino superior como bem público ou como bem privado}

O debate envolvendo a questão do ensino superior como bem público (bem coletivo) ou como bem privado (individual) parece ser bastante recente, embora possa ter raízes econômicas e políticas antigas, difusas ou não, contemporâneas da formação do Estado liberal, e presentes em obras como a Riqueza das naçôes, de Adam Smith (no capítulo "Da despesa das instituiçôes para a educação da juventude"). ${ }^{4}$ $\mathrm{O}$ que se discute neste texto essencialmente não é se a educação em geral e o ensino superior em particular são bens públicos ou privados (com ou sem fins lucrativos), mas, entre outras coisas, que funções deveriam cumprir e qual era a melhor forma de garanti-los, se com subsídio integral ou apenas parcial do Estado. Os objetivos da utilidade, da eficiência e da eficácia do empreendimento educativo, retomados à outrance hoje pelos ultraliberais, já ali se faziam presentes.

Nesse texto, além de enfatizar - como Hobbes já o fazia em $O$ Leviatã - a competitividade entre homens, organizações e instituições de toda a natureza, inclusive as educacionais, como princípio funda- 
mental do progresso; além de desqualificar a escola pública, em especial quando integralmente subsidiada pelo tesouro do Estado - "Desse modo, as dotações das escolas e colégios não só corromperam a diligência dos professores públicos, como tornaram impossível a existência de bons professores particulares" -, Adam Smith afirma, de modo bastante ambíguo, que, se não houvessem instituições públicas destinadas à educação, só seria ensinado o que fosse imediatamente útil (1983, p. 415). De qualquer modo, Adam Smith enfatizou a necessidade da atenção do Poder Público, mediante a educação, "para impedir a quase total corrupção e degeneração da grande maioria das pessoas", especialmente do trabalhador envolvido com as operaçóes muito simples e rotineiras do trabalho de que se ocupa, que deixa de exercitar sua capacidade intelectual ou suas habilidades para solucionar problemas e torna-se "tão estúpido e ignorante quanto é possível conceber-se numa criatura humana”.

É a educação da gente comum, "numa sociedade civilizada e comercial", a que requereria maior atenção do Poder Público, muito mais que a das pessoas de posição e fortuna. A preocupação com a economia de custos também já ali se fazia presente: "Com uma despesa bastante reduzida o público pode facilitar, encorajar e mesmo impor a necessidade da acquisição dessas partes mais essenciais da educação [ler, escrever e contar] ao conjunto das pessoas" (1983, p. 421).

Mas o ensino seria pago, ainda que a baixo custo, pela família (para ser valorizado), e o mestre ("mercenário" e propenso à vadiagem?) seria pago apenas em parte pelo Poder Público, "porque se fosse totalmente ou na sua grande parte pago por ele, depressa aprenderia a negligenciar a sua actividade" (idem, ibid. Grifos nossos).

Esse debate está presente, embora de forma transversal, também nos críticos do modo de produção capitalista e da sociedade liberal-burguesa, como no texto de Karl Marx Crítica do Programa de Gotha: observações à margem do Programa do Partido Operário Alemão (s/d.), de 1875. Neste, Marx, em lugar de discutir se a educação é um bem público ou privado, diante do tipo de sociedade e de Estado (prussiano-alemão) com que se defronta, expõe sua profunda descrença em que "a educação pode ser igual para todas as classes", como propunha esse programa partidário, além de constatar que à época "a modesta educação dada pela escola pública" era "a única com- 
patível com a situação econômica, não só do operário assalariado mas também do camponês". Estranhava a reivindicação dos socialistas do Partido Operário por educação obrigatória e gratuita para todos, não porque não visse na educação um bem público a ser garantido pelo tesouro do Estado, mas, antes de tudo, porque queria ver o Estado (prussiano-alemão) o mais distante possível da educação do povo:

Uma "educação popular a cargo do Estado" é completamente inadmissível (...). Longe disso, o que deve ser feito é subtrair a escola a toda a influência por parte do governo e da Igreja. Sobretudo no Império Prussiano-Alemão (e não vale fugir com o baixo subterfúgio de que se fala de um "Estado futuro"; já vimos o que é este), onde, pelo contrário, é o Estado que necessita de receber do povo uma educação muito severa. (s/d., p. 223)

Em segundo lugar, porque via no ensino superior "gratuito" em alguns estados norte-americanos, à época, uma forma de privilégio das "classes superiores" (as únicas e em porcentual baixíssimo a atingirem esse nível de ensino), que teriam seus estudos pagos com as receitas gerais dos impostos. E fazia um paralelo com o que acontecia com a "administração gratuita da justiça", também reivindicada pelo programa dos socialistas alemães:

A justiça criminal é gratuita em toda a parte; a justiça civil gira quase inteiramente em torno dos pleitos sobre a propriedade e afeta, portanto, quase exclusivamente às classes possuidoras. Pretende-se que estas decidam suas questões à custa do tesouro público? (Idem, ibid.)

O filólogo e historiador Mário A. Manacorda alerta, em Marx y la pedagogía de nuestro tiempo (s/d., p. 45-46), que Marx, tanto ao expor sua descrença na igual educação para todos quanto para execrar a presença do Estado e da Igreja na educação, pensava na sociedade e no Estado de seu tempo. Quem, como Marx, defendeu, no Manifesto de 48, em $O$ capital e nas Instruçôes aos delegados (do Comitê Provisório de Londres ao I Congresso da Associação Internacional de Trabalhadores, em Genebra, em 1866), a essencial vinculação da educação ao trabalho produtivo como forma de emancipação operária e arma revolucionária para a tomada do poder e superação da sociedade burguesa, não poderia descrer do princípio da educação igual para todos, nos seus diferentes níveis, nem da importância, na sua promoção, de um futuro Estado democrático. O que dá sentido a sua crítica nos termos acima é sua 
convicção de que os direitos de cidadania são condicionados historicamente pela economia, pela política, pela cultura etc., isto é, pelas condições infra e superestruturais vigentes em cada época.

São essas condições objetivas que condicionam o discurso ideológico da valorização da educação para todos, nos seus variados graus, e a sua prática efetiva ao longo do tempo. São elas que explicam a proeminência da questão do conhecimento, da ciência e da educação, quando da irrupção de movimentos revolucionários, como a Revolução Francesa, a Comuna de Paris, as Revoluções Russa, Chinesa e Cubana. Nesses momentos, o pano de fundo para as campanhas de alfabetização em massa, para a construção de escolas tecnológicas ou politécnicas, para o incentivo a que todos tenham acesso ao máximo de saber e qualificação é a idéia de que o conhecimento, a ciência e a educação não se reduzem a, nem podem ser essencialmente, uma mercadoria ou commodity qualquer (rivalidade e excluibilidade), ${ }^{5}$ mas que são fundamentalmente um bem público, coletivo, fruto do trabalho humano solidário ou explorado nas relações de produção capitalistas, um bem que não se desgasta, não se degrada, mas, ao contrário, cresce e multiplica-se pelo uso individual e coletivo e constitui-se em parte essencial dos direitos humanos de cidadania.

Igualmente quando da vigência do Estado do Bem-Estar, tanto em países de maior tradição educacional republicana e pública quanto nos em que a educação era garantida por instituições privadas, embora sem fins lucrativos, não esteve em geral em questão o estatuto público ou privado da educação, mas sua relevância para o desenvolvimento menos excludente das nações, para o reforço da solidariedade entre ricos e pobres, e para que todos tivessem cada vez maiores e melhores chances de ter acesso aos benefícios do trabalho humano coletivo. Por isso, até o advento da Era Thatcher, por exemplo, 95\% dos custos de manutenção do sistema universitário inglês foram garantidos pelo fundo público. ${ }^{6}$

É quando as condições objetivas da economia e da política, somadas a uma interpretação teórica "conveniente" da crise do Estado do Bem-Estar, fazem-se presentes e tendem a se tornar hegemônicas que o debate do conhecimento, da ciência e, em especial, do ensino superior, como bem público ou privado, entra incisivamente em cena. 
Sem pretender maior precisão, pode-se indicar que esse debate, no que concerne especificamente ao ensino superior, ${ }^{7}$ tem início mais evidente na década de 1980. Em documento de 1986, intitulado Financing education in developing countries - An exploration of policy options (WB, 1986), o Banco Mundial defende de forma exaustiva a famosa tese do maior retorno social e individual dos investimentos em educação básica que o dos investimentos em educação superior. Aliás, essa tese irá sofrer uma atualização revisora do Banco em 2000, dessa vez em documento oficialmente elaborado em parceria com a UNESCO e que se intitula Higher education in developing countries: peril and promise (WB, 2000), que será comentado mais adiante.

A partir de 1986, esse estudo, preparado pelo Research Division of the World Bank's Education and Training Department, ${ }^{8}$ com o alerta de praxe de que os julgamentos nele expressos não refletem necessariamente o ponto de vista do World Bank's Board of Executive Directors or of the governments that they represent, obteve uma enorme repercussão entre os países, especialmente os da periferia ou semiperiferia envoltos em crônicos déficits públicos.

Objetivando induzir os países em desenvolvimento a investirem seus parcos recursos públicos prioritariamente na educação primária e, posteriormente, na educação secundária, ao mesmo tempo em que recomendava a diminuição dos investimentos públicos na educação superior e a diversificação de suas fontes de recursos (fim da gratuidade e imposição de taxas de matrículas e mensalidades), o documento apresenta o que julga "Considerável evidência (...) acerca do retorno privado e social dos investimentos em educação tanto nos países desenvolvidos como nos em desenvolvimento". Da comparação da produtividade ao longo da vida de trabalhadores com diferentes níveis de escolaridade com os custos sociais ou privados da educação, apesar de substanciais variações entre países, o documento vê emergirem claros padrōes:

- A educação primaria é a mais produtiva forma de investimento, seguida pela educação secundária e, finalmente, pela educação superior.

- O retorno é muito mais alto nos países pobres e declina de acordo com o nível do desenvolvimento econômico. 
- Porque os subsídios são altos em muitos países, as taxas de retorno privado são consistentemente mais altas que as de retorno social, particularmente na educação superior.

- Em poucos países para os quais os dados estão disponíveis, o retorno para a educação tem permanecido relativamente estável ao longo do tempo. (WB, 1986, p. 8)

Esses padrões são exaustivamente demonstrados mediante resultados de uma série de pesquisas e vão servir de argumentos e premissas, aparentemente irrefutáveis, para as "Opçōes políticas" (assim se intitula o $3^{\circ}$ capítulo) sugeridas aos governos dos países ricos e especialmente dos pobres, e que podem ser assim resumidas: transferir parte do montante dos recursos de manutenção da educação superior, hoje garantido pelo Estado, para a responsabilidade dos estudantes e suas famílias, e dar nova alocação aos recursos públicos destinados à educação. Isso deveria ser feito: a) realocando os gastos governamentais para "o nível com mais alto retorno social" [escola primária] e diminuindo o gasto público da educação superior; b) criando um mercado de crédito para a educação, com bolsas seletivas, mormente na educação superior; c) descentralizando a gestão da educação pública e incentivando a expansão de escolas privadas e comunitárias (WB, 1986, p. 17).

Prevendo as dificuldades de viabilizar esse conjunto de medidas, o documento sugere uma série de estratégias ou formas específicas de realocação dos recursos públicos para "expandir a mais produtiva forma de investimento educacional (que é freqüentemente a escola primária)" e "redirecionar os subsídios estatais dos grupos socioeconômicos mais ricos para os mais pobres (...)". O esforço de convencimento dos responsáveis pelas políticas públicas de educação, quanto à pertinência dessas açôes visando ao pagamento individual e familiar dos "serviços educacionais", leva os autores a afirmarem, no preâmbulo do item "Aumentar as contribuiçõoes privadas nos níveis secundário e universitário", o que segue:

Evidências demonstram que as pessoas estão dispostas a pagar pela educação. $\mathrm{Na}$ África, o retorno privado assegurado pela educação superior tem sido tão alto que, mesmo após a redução do crédito educativo ou a imposição de taxas, a educação superior ainda continuará sendo um atrativo para investimentos pessoais. (WB, 1986, p. 17) 
Sobre as conseqüências desse documento para as políticas públicas de educação em geral e de educação superior em particular, os próprios relatórios anuais do Banco e seus documentos posteriores relacionados à educação irão regularmente dar conta. Mas, como exemplo, vale o relato de Marco Antonio Dias, então Diretor da Divisão de Ensino Superior da Unesco, quando diz que o ex-presidente da Tanzânia, Julius Nyerere, em visita ao Conselho Executivo dessa organização mundial, lamentava que seu país, apesar de uma política voluntarista implementada logo após a independência na alfabetização e educação básica, tenha cometido um grave erro:

Por seguir os conselhos de especialistas internacionais, deixou de dar atenção particular ao ensino superior e, hoje, verifica-se que não dispõe de quadros nem de pesquisadores necessários ao seu desenvolvimento. Em contrapartida, muito do que foi feito em educação de base perdeuse, pois faltaram condições para assegurar a qualidade em razão de deficiências na formação de professores e na preparação de pesquisadores em educação, que normalmente são formados pelas universidades. Dirigindo-se, em particular, a seus colegas africanos, Julius Nyerere acentuou: "Não cometam o mesmo erro que nós". (Dias, 1996, p. 25)

No talvez mais famoso documento elaborado pelo Banco Mundial sobre educação superior nas últimas décadas, Higher education: the lessons of experience (1994), essa tese é reiterada, em contexto em que as "opções políticas" sugeridas pelo documento de 1986 já eram largamente acatadas e postas em prática por muitos países. No documento, dá-se destaque especial ao Chile (de Pinochet), elogiado por ter não apenas seguido à risca as sugestões mas por ter ido muito além delas, tornando-se, então, um exemplo a ser seguido, uma das "lições da experiência".?

Nesse documento, além de um diagnóstico da crise da educação superior, tendo como pano de fundo o déficit público dos países pobres, os supostos modelo único de universidade de pesquisa e excessivo comprometimento com ela do fundo público, ${ }^{10}$ utiliza-se também dessa tese - do maior retorno individual e social dos investimentos em educação básica - para justificar uma série de recomendaçôes, que retomam, aprofundando, recomendaçôes anteriores, às quais se acrescem outras tantas. É nesse documento que se defende com grande vigor e insistência, entre outras ações: a maior diferenciação institucional, 
"incluído o desenvolvimento de instituições privadas"; e a criação de incentivos "para que as instituiçôes públicas diversifiquem as fontes de financiamento, por exemplo, a participação dos estudantes nos gastos e a estreita vinculação entre financiamento fiscal e os resultados" (WB, 1994, p. 4 e 29).

A retomada dessa tese, que explicitamente se verifica em diferentes momentos do texto, aparece claramente quando se afirma: "No entanto, no setor de educação há provas de que as inversões no nível terciário têm taxas de rentabilidade social mais baixas que as inversões no ensino primário e secundário (...).” (WB, 1994, p. 14).

É a partir de 1994, no caso do Brasil, que se inicia um consistente processo de redução de gastos públicos federais para o conjunto das instituições federais de ensino superior (IFES) e se desencadeia a retomada, em grau muito mais aprofundado que na década de 1970, sob a ditadura militar, da privatização desse nível de ensino, como se verá adiante.

Do ponto de vista estratégico, para o convencimento geral e o respaldo de políticas públicas conducentes à reforma educacional preconizada pelo Banco Mundial, faltava complementar essa tese com outra, que seria oportunamente desenvolvida em documento publicado pelo Banco em 1998: The financing and management of higher education - A status report on worldwide reforms ${ }^{11}$ (WB, 1998).

Nesse documento se afirma de entrada que se estaria verificando, na década de 1990, um "movimento surpreendentemente homogêneo de reforma do financiamento e gestão das universidades e outras instituições de ensino superior" e que isso ocorria "em países com sistemas políticos e econômicos e tradições docentes muito diversos e que se encontram em fases muitos diferentes de desenvolvimento industrial e tecnológico" (WB, 1998, p. 2). É importante notar que o documento identificava, nessas reformas marcas, em geral, anteriormente colhidas das "lições da experiência" e sugeridas pelo Banco, tais como: expansão de matrículas e de instituições de ensino superior (IES) cada vez mais diferenciadas; pressão fiscal com nível baixo e decrescente do custo/aluno; importância das orientaçôes e soluçóes do mercado; busca de recursos não-estatais (idem, ibid.).

É nesse documento que, entre outras constataçôes ou liçôes da experiência, identifica-se, na prática dessas reformas, que elas estariam 
Universidade pública estatal: entre o público e o privado/mercantil

muito mais "orientadas para o mercado do que para a propriedade pública ou para a planificação e regulação estatais" e afirma-se que isso se deveria à "crescente importância que em quase todo o mundo têm adquirido o capitalismo de mercado e os princípios da economia neoliberal' 12 (idem, ibid., p. 4; grifos nossos).

Nada mais oportuno que introduzir aqui a tese do ensino superior como bem antes privado que público. Apoiando-se na obra de Nicholas Barr, The economics of the Welfare State, (1993, p. 106, 345) afirma o documento:

O ensino superior responde a muitas das condições identificadas por Barr como características de um bem privado, que se pode subordinar às forças do mercado. Em primeiro lugar, o ensino superior não pode ser tratado como um bem estritamente público. Isso se deve a suas condições de competitividade (oferta limitada), excluibilidade (seguidamente se pode obtê-lo mediante pagamento) e recusa (não é requerido por todos), todas características que não respondem às de um bem estritamente público, mas sim às de um bem privado. Em segundo lugar, os consumidores do ensino superior estão razoavelmente bem informados e os provedores freqüentemente estão mal informados - condições ideais para o funcionamento das forças do mercado. (WB, 1998, p. 5; grifo nosso)

Correta ou não, esta tese - que desconsidera o fato geralmente aceito de que o conhecimento (objeto principal do ensino superior) é um bem público global ${ }^{13}$ - tem servido de complemento e reforço à tese do menor retorno social da educação superior com relação à educação básica $\mathrm{e}$ fortalecido as políticas públicas conducentes à significativa deserção do Estado da manutenção dos sistemas públicos de educação superior, ao incentivo à proliferação das instituiçôes privadas, com e sem fins lucrativos, em geral de baixa qualidade, e à própria semiprivatização da universidade pública por diferentes mecanismos de utilização privada das funçôes e dos produtos dessas instituiçôes, via, por exemplo, no caso do Brasil, as centenas de fundações (privadas) de apoio institucional.

Esse documento, que teria sido a contribuição do Banco para a Conferência Mundial sobre o Ensino Superior, organizada pela UNESCO, de 5 a 9 de outubro de 1998, alimentaria, portanto, um debate que estará no centro das preocupações dessa Conferência, assim como esteve no de suas conferências regionais preparatórias, em especial as de Havana e Tóquio. 
No Documento de Trabalho Vers un Agenda 21 pour l'enseignement supérieur - Défis et tâches dans la perspective du XXI siècle à la lumière des conférences régionales, recupera-se um conjunto articulado de declarações a respeito do tema, emanadas dessas conferências regionais preparatórias para a Conferência Mundial de Paris:

As crescentes necessidades do ensino superior conduzem suas instituições a buscar fontes suplementares de financiamento. Seus esforços merecem ser encorajados e apoiados pela sociedade e acima de tudo pelos poderes públicos. Isto posto, sendo o ensino superior "um bem público" (Havana, Tóquio) e tendo que exercer "um papel-chave na abertura de novas vias para o futuro" (Palermo), "o Estado não pode renunciar à responsabilidade de seu financiamento" (Havana), cabe-lhe assumir a responsabilidade principal do financiamento do ensino superior (Dacar, Tóquio), ao governo cabe assegurar "medidas estáveis de financiamento" (Palermo), e "é o Estado que deve ser o responsável principal pelo financiamento do ensino superior" (Beirute).

No discurso de encerramento da Conferência, "O futuro do ensino superior em uma sociedade em transformação e seu papel essencial no desenvolvimento humano", Céline Saint-Pierre, presidente do Conselho Superior de Educação do Québec, proclamava: "É preciso reafirmar que o ensino superior deve ser definido como um serviço público e não como uma empresa do saber e de formação orientada pelas leis do mercado". (WB, 1998, p. 80).

No Artigo 14 da Declaração Mundial sobre a Educação Superior no Século XXI - Visão e ação, intitulado "O financiamento da educação superior como serviço público”, afirma-se:

La financiación de la educación superior requiere recursos públicos y privados. El Estado conserva una función esencial en esa financiación. (...) El apoyo público a la educación superior y a la investigación sigue siendo fundamental para asegurar que las misiones educativas y sociales se llevan a cabo de manera equilibrada.

Em setembro de 1998, às vésperas dessa Conferência, segundo Dias (2003b, p. 8), em documento considerado então restrito (WTO, 1998. Council for Trade Services. Background Note by the Secretariat. SCW49, 23/9/1998), 
Universidade pública estatal: entre o público e o privado/mercantil

(...) el secretariado de la OMC [Organização Mundial do Comércio] insinuaba una tesis - en realidad un gran sofisma - según la cual, desde que se permite la existencia de proveedores privados en la educación, los gobiernos aceptan el principio de que la educación, y en particular la educación superior, puede ser tratada como servicio comercial, y en consecuencia, debe ser regulada por la OMC.

Dias, ao proferir Aula Inaugural na Universidade Politécnica da Catalunha, contesta essa opinião, enfatizando:

En realidad, la educación es un bien público, los gobiernos soberanos tienen el derecho de delegar esa función a instituciones de la sociedad civil, dentro de reglas y leyes basadas en un sistema de concesiones, autorizaciones o delegaciones que deben someterse a estrictos controles. (Idem, ibid.)

Stiglitz, ex-economista-chefe do Banco Mundial, a respeito do conhecimento como bem público global, escreve em caráter pessoal (como afirma) em 1999:

Sem dúvida, para adquirir e usar conhecimento, os indivíduos podem ter que efetuar despesas - assim como teriam que gastar para retirar água de um lago público. $\mathrm{O}$ fato de que possa haver custos significativos associados à transmissão de conhecimento não afeta em nada a natureza de bem público do conhecimento: provedores privados podem assegurar a "transmissão" por uma taxa que reflita o custo marginal da transmissão, enquanto, ao mesmo tempo, o bem em si pode manter-se gratuito. (1999)

Aliás, o debate ensino superior como bem público ou privado acirrase com a proposta presente na Agenda do Acordo Geral sobre Comércio em Serviços (AGCS), da OMC, de liberalização comercial dos "serviços educacionais". ${ }^{14}$ Segundo Dias, quando o AGCS diz que estão cobertos todos os serviços, esses serviços não estariam explicitados, e foi o secretariado da OMC que, em outubro de 1999, "unilateralmente, por meio de um documento intitulado 'Introdução ao AGCS', definiu expressamente os serviços que, a seu critério, deveriam ser regulados pelo AGCS, incluindo a educação" (2003b, p. 9).

A partir de 2000, la organización comenzó negociaciones para la liberalización de los servicios educativos. En una operación aparentemente articulada, Estados Unidos, Australia y Nueva Zelanda propusieron a los demás países una apertura prácticamente sin límites de sus mercados a los proveedores oriundos de sus territorios, y solicitaron que toda restricción a la 
acción de esos grupos por los gobiernos nacionales fuera rechazada. (Dias, 2003b, p. 9)

No âmbito do Banco Mundial, a primeira reação contrária à tese do menor retorno social dos investimentos em educação superior (e, em certa medida, contra sua privatização indiscriminada) dá-se, como já dito, no documento Higher education in developing countries: peril and promise (de $1^{\circ}$ de março de 2000). Como sempre e porque oficialmente teria sido produzido em parceria com a UNESCO, deve-se lembrar o alerta de praxe de que não traduz necessariamente as posições oficiais do Banco. Tratar-se-ia de mais um documento estimulando o debate, sem que necessariamente fosse alterada qualquer das linhas diretrizes da política para o ensino superior do Banco? Afinal, sabia-se que o Banco Mundial não iria abandonar, de uma hora para outra, sua parceria com o FMI, suas referências econômico-políticas, sua valorização das virtudes do mercado, sua visão do ensino superior como um bem de interesse individual e privado, de afastamento do Estado com relação ao ensino superior, de avaliação deste em termos de custo/benefício (Sguissardi, 2000, p. 71).

Assim como já havia ocorrido com o documento The financing and management of higher education (1998), ao ser publicado esse novo documento, o processo de ajuste neoliberal da economia e suas correspondentes reformas do papel do aparelho do Estado, sintetizados no Consenso de Washington - equilíbrio orçamentário, redução do déficit público e dos gastos nos setores sociais; abertura comercial; liberalização financeira; desregulamentação dos mercados domésticos; privatização de empresas de serviços públicos de energia, telecomunicações, saúde e educação -, já se encontravam em estado avançado na maioria dos países do centro e da periferia. As orientaçôes e recomendações dos documentos do Banco Mundial aqui comentados, de 1986 e 1994, haviam sido seguidas, como lembrava anteriormente o presidente Julius Nyerere.

De imediato destaque-se a consideração que esse novo documento faz acerca do conhecimento como um bem público internacional cujos benefícios deveriam ultrapassar as fronteiras dos países onde tenha sido produzido (WB, 2000, p. 35). A análise do documento inteiro, entretanto, permite levantar a hipótese de que a posição divergente tomada pelos autores do documento quanto a teses anteriormente patrocinadas 
Universidade pública estatal: entre o público e o privado/mercantil

pelo Banco não se faz com relação a diretrizes e ações essenciais tradicionais, a menos do que de fato se configuraria no trecho, entre outros, de teor similar:

Desde os anos de 1980 muitos governos nacionais e organismos financiadores internacionais têm atribuído à educação superior um nivel de prioridade relativamente baixo. As análises econômicas, de olhar estreito -e, em nossa opinião, equivocado - têm contribuido para formar a opinião de que o investimento público em universidades e em instituições de educação superior se traduziria em ganhos insignificantes em comparação com os ganhos do investimento em escolas primárias e secundárias; assim como de que a educação superior aumenta exageradamente a desigualdade de ganhos. (WB, 2000, p. 11; grifos nossos)

O documento faz um claro e bem articulado discurso em defesa das potencialidades da educação superior. Acredita que ela tem importância fundamental, quando "o saber suplanta o capital físico como fonte da riqueza atual”, na diminuição do imenso gap existente entre países ricos e pobres e, inclusive, na promoção dos valores de uma democracia pluralista.

Para o que interessa aqui, vale destacar sua bem articulada crítica e re-atualização da teoria do capital humano, embora envolta em renovado e acrítico otimismo pedagógico. Crê-se que "os argumentos econômicos tradicionais [Teoria do Capital Humano] são fundados num limitado entendimento da contribuição [taxa de retorno social e de interesse público] da educação superior". Esse "limitado entendimento" é que teria conduzido o Banco a concluir:

(...) que a sua estratégia de empréstimo deveria enfatizar a educação primária, relegando a educação superior a um lugar relativamente menor na sua agenda de desenvolvimento. O posicionamento do Banco Mundial tem sido influente e muitos outros doadores também têm enfatizado a educação primária, e num certo sentido a [educação] secundária, como um instrumento para promover desenvolvimento econômico-social. (Idem, ibid.)

Ainda que o documento mantenha confiança no mercado, ao reconhecer sua intrínseca necessidade objetiva de busca de lucro, não o vê mais como solução para todas as demandas de expansão da educação superior e reforça a exigência do concurso do Poder Público, com o papel de supervisor, além de, e de forma também incomum 
nos documentos do Banco, valorizar a capacidade criativa dos "profissionais da educação superior":

Evidentemente que por si o mercado não vai criar esse tipo de sistema. Os mercados requerem lucros e isso pode relegar importantes oportunidades e deveres de ensino. As ciências básicas e as humanidades, por exemplo, são essenciais para o desenvolvimento nacional, mas seguramente recebem recursos insuficientes, a menos que os líderes educacionais, os que contam com recursos para pôr em prática suas visões, promovam-nas ativamente. É necessário que os governos desempenhem um novo papel como supervisores da educação superior, mais que como gestores. Deveriam concentrar-se em estabelecer os parâmetros dentro dos quais se possa alcançar o êxito, enquanto permitem que as soluções específicas aflorem das mentes criativas dos profissionais da educação superior. (Idem, ibid., p. 11)

Análises de viés economicista persistem no documento, acreditando seus autores que a competitividade é um fator de grande qualidade, a ser garantida pela multiplicação das IES privadas, pela introdução do ensino pago nas IES públicas, pela ampliação da diferenciação institucional e pelas novas fontes alternativas de recursos, entre outras medidas. Acredita-se, também, na parceria de instituições públicas (mas com ensino pago) e privadas, com e sem fins de lucro: "Todos os tipos de IES - inclusive as que operam por filantropia ou em razão do lucro podem servir ao interesse público". Mais uma vez, de modo inusitado, o documento alerta para a fragilidade das instituições privadas stricto sensu (for profit):

Mesmo quando o mercado opera bem e os estudantes recebem um bom serviço, as instituições privadas podem ainda assim falhar no servir ao interesse público. As instituições com fins lucrativos precisam operar como um negócio, enfrentando a competição do mercado e tentando maximizar o retorno de seu investimento. (Idem, ibid., p. 37)

Apesar de se tentar, ao longo do documento, a conciliação entre a imprescindibilidade do Estado e as virtudes do mercado - "O sistema como um todo precisa beneficiar-se do vigor e do interesse do mercado e do Estado" -, reconhecem-se os sérios problemas de qualidade postos pela diferenciação institucional - uma das mais importantes consignas dos documentos anteriores do Banco, como já vimos - e conclui-se afirmando que "O argumento de que as forças do mercado irão garantir uma boa qualidade é simplista” (idem, ibid., p. 32). 


\section{O confronto estatal/público X privado/mercantil}

O dilema que atualmente se põe para a universidade estatal pública - bem público versus privado/mercantil - constituiu-se gradativamente ao longo das últimas três décadas. Serviram de base para tanto, como já dito, as crises e novas concepçôes da economia e do papel do Estado, o discurso teórico-pragmático dos organismos multilaterais, em especial financeiros, e as políticas econômico-sociais e educacionais praticadas por países centrais e periféricos, coerentes com essas concepçôes e com esse discurso. Antes de examinar alguns aspectos dessas políticas postas em prática no Brasil no último decênio, considere-se um pouco mais as estratégias desse discurso ideológico que tem assolado a opinião pública, via re-semantização de conceitos outrora de profundo sentido positivo para os que defendem o conhecimento, a educação e o ensino superior, no caso, como bens públicos universais.

Apenas para ilustrar de passagem, observe-se o que Bourdieu \& Wacquant, em artigo de maio de 2000, publicado no Le Monde Diplomatique sob o título "La nouvelle vulgate planétaire", escrevem a respeito da que chamam nova lingua dos tempos atuais. Um grande acervo de termos novos, ou nem tanto, seria utilizado para fazer a cabeça da população, da grande imprensa, dos executivos das empresas nacionais e multinacionais e dos funcionários da mão direita do Estado, como diria o próprio Bourdieu (1998) já em 1992. Entre eles,

(...) "mundialização" e "flexibilidade"; "governança" e "empregabilidade"; "underclass" e "exclusão"; "nova economia" e "tolerância zero"; "comunitarismo", "multiculturalismo" e seus primos "pós-moderno", "etnicidade", "minoridade", "identidade", "fragmentação" etc. (Bourdieu \& Wacquant, 2000)

Em contraposição, constatam a ausência de termos ou conceitos tais como “'capitalismo', 'classe', 'exploração', 'dominação', 'desigualdade”. Consideram Bourdieu \& Wacquant que "tantos vocábulos peremptoriamente revogados sob o pretexto de obsolescência ou de impertinência presumidas - é o produto de um imperialismo propriamente simbólico", que, insidiosamente, vai se tornando senso comum.

Essa vulgata moderna não estaria sendo utilizada apenas pelos neoliberais ou ultraliberais, que desconsideram todas as conquistas 
sociais anteriores. Utilizam-na abertamente, e a cada dia mais, pesquisadores, escritores, artistas e militantes de esquerda que se pensam progressistas.

No seu livro Educando à direita - Mercado, padrões, Deus e desigualdade (2003a) e em seu artigo "Aliança estratégica ou estratégia hegemônica? Conservadorismo entre os desprovidos" (2003b), Michael Apple aprofunda ainda mais o exame dessa questão, tratando-a na perspectiva da compreensão da avalanche conservadora que varre o campo social e educacional em todos os níveis. Além da supervalorização de termos e expressōes como mercado, liberdade de escolha e prestação de contas, o campo educacional é invadido por termos e expressões como:

(...) quase-mercado educacional, forças do mercado, decisões privadas, regulação, regulação pela oferta e pela procura, desregulação, controle, ranking, competências, qualidade total, acreditação, bem privado x bem público, eqüidade social, livre escolha escolar, escolas autogestionadas, organizações sociais, organizações públicas não-estatais, produtos paraescolares, capitalismo acadêmico etc. (Camargo et al., 2003, p. 730)

Passa a ter um papel central nessa discussão a contraposição estatal/público versus privado/mercantil, que o sociólogo Emir Sader apresenta, em sucinta e oportuna análise recente (2003). ${ }^{15}$ Indo ao ponto crucial da questão, Sader começa por enfatizar que "Uma das operações teóricas e políticas mais bem-sucedidas do neoliberalismo foi instaurar os debates em torno da oposição entre estatal e privado". Ao contrapor o estatal ao privado teria o discurso neoliberal deslocado o eixo do debate para "um campo duplamente favorável ao liberalismo". Isso permitiria "uma mais fácil desqualificação do estatal" e tiraria de cena um dos termos essenciais dessa polêmica: $o$ público.

Esta nova contraposição se prestaria a uma mais eficaz caracterização do estatal como "ineficiente", "burocrático", "corrupto", "opressor", cavador de impostos e mau prestador de serviços, e, do privado, como "espaço de liberdade individual, de criação, imaginação, dinamismo".

Verifica Emir Sader, como já o fizeram outros analistas desde René Dreifuss, em seu clássico 1964: a conquista do Estado (1981), o contínuo processo de privatização do Estado brasileiro, que o tem tor- 
Universidade pública estatal: entre o público e o privado/mercantil

nado um Estado privatizado, razão principal de sua desqualificação crônica:

Um Estado que arrecada do mundo do trabalho e transfere recursos para o setor financeiro, gastando mais com o pagamento dos juros da dívida do que com educação e saúde. Um Estado que paga taxas de juros estratosféricas ao capital financeiro, mas remunera pessimamente seus professores e seus trabalhadores do setor de saúde pública, aqueles mesmos que prestam serviços à massa da população. Um Estado que não assegura os direitos básicos para a grande maioria da população, mas que dilapidou o patrimônio público em processos de privatização financiados com o próprio dinheiro público. (Sader, 2003, p. 3)

É diante desse espectro de um Estado nefasto aos interesses gerais e individuais que, para o autor, "o privado surge como pólo privilegiado", sacralizado, panacéia para os males crônicos do Estado brasileiro.

Mas o traço mais eminente dessa operação foi a redução do debate a estes dois termos, como se eles necessariamente se constituíssem em dois pólos contrapostos. Na realidade, como demonstra o autor, "o estatal não é um pólo, mas um campo de disputa, que nos nossos tempos é hegemonizado pelos interesses privados". Da mesma forma que

(...) o privado não é a esfera dos indivíduos, mas dos interesses mercantis - como se vê nos processos de privatização, que não constituíram processos de desestatização em favor dos indivíduos, mas das grandes corporações privadas, aquelas que dominam o mercado -, a verdadeira cara por trás da esfera privada no neoliberalismo. (Idem, ibid.)

A constatação das práticas da política econômica brasileira dos anos recentes, que presidiu o processo de privatização de grandes empresas estatais, conduz o autor à afirmação de que, nesse esquema, o pólo oposto ao estatal, ao invés de espaço do indivíduo e das liberdades individuais, é "a negação da cidadania, é o reino do mercado, aquele que, negando os direitos, nega a cidadania e o indivíduo como sujeito de direitos". Portanto, a conclusão: "A polarização essencial não se dá entre o estatal e o privado, mas entre o público e o mercantil".

Tirando algumas conseqüências para a compreensão do dilema que hoje enfrenta a universidade estatal pública, o fato de ser estatal, 
do ponto de vista de seu regime jurídico e da sua manutenção exclusiva ou não por parte do tesouro do Estado, não é garantia de que ela possa ser definida como bem público, como universidade pública. Independentemente de seu estatuto jurídico-formal, pode estar sendo privatizada. E ao ser privatizada pelas diferentes formas de administração e financiamento, autonomia/heteronomia, avaliação/accountability, produção e transmissão do conhecimento, pode estar sendo conduzida a situar-se no espaço do privado/mercantil. A essência do público, diz Sader, é "a universalização dos direitos", ao passo que a do mercado é "a mercantilização do acesso ao que deveriam ser direitos: educação, saúde, habitação, saneamento básico, lazer, cultura" (2003, p. 3).

Que a educação e, em particular, a educação superior estão sendo, cada vez mais, tratadas como bens privados, commodities, não há necessidade de demonstração: as atividades de provedores privados/ mercantis como o Consórcio Sylvan Learning Systems ${ }^{16}$ e o Grupo Apollo Internacional, Inc. seriam suficientes para ilustrá-lo, ou declarações como a atribuída a Klor de Alva, diretor desse segundo grupo, em recente conferência no Brasil: "A educação é um negócio e, como tal, deve ser gerenciada como um empreendimento do mundo corporativo, com base na busca de resultados" (Revista do Ensino Superior, 2004, p. 22).

Em contrapartida, que a mão direita do Estado, no Brasil e em muitos países do mundo, não está preocupada com o avanço desse discurso e dessa prática e que ignora o que defende e eventualmente faz a sua mão esquerda o demonstram suas políticas públicas de educação superior, em particular na última década. Com relação ao caso brasileiro, veja-se sucintamente, nas páginas que seguem, alguns dados e fatos a respeito.

Traços universais e marcas domésticas das políticas de educação superior no Brasil: entre o público e o privado/mercantil

As políticas de educação superior no Brasil na última década, em linhas gerais, têm sido caracterizadas por alguns traços bastante similares aos que identificam essas políticas em outros países, centrais ou periféricos, como Inglaterra, Austrália, Chile, Argentina etc. (Sguissardi, 2003). 
Seu pano de fundo econômico-financeiro tem sido o ajuste neoliberal da economia, em que se destacaram a abertura comercial, a liberalização financeira, a desregulamentação dos mercados e das relações trabalhistas, a reforma previdenciária, a obtenção, a qualquer custo, do equilíbrio orçamentário e do controle da inflação, via redução dos gastos públicos, aumento de taxas de juros pelo Banco Central, o inadiável pagamento da dívida externa e a privatização das empresas estatais, com transferência para a iniciativa privada de obrigaçôes tradicionalmente de responsabilidade do Estado.

Complementarmente, seu pano de fundo político-administrativo tem sido a reforma do aparelho do Estado, pós-burocrática, declaradamente gerencialista (BRASIL, MARE, 1995), apoiada em concepções de Estado subsidiário, avaliador e controlador. No caso brasileiro, a proposta de transformação de sua meia centena de instituições federais de ensino superior (IFES) em organizações sociais (entidades de direito privado), no conhecido programa de publicização do Estado e tendo como principal instrumento os "contratos de gestão", ilustra muito bem o terreno em que se movem essas políticas.

Como em muitos países centrais e periféricos, as políticas de educação superior caracterizam-se pela redução permanente do financiamento estatal da educação superior pública, pelo estancamento de sua expansão, pelo congelamento salarial do staff universitário, pela perda de direitos trabalhistas, pela flexibilização dos contratos de trabalho, diferenciação institucional, diversificação de fontes de financiamento, e pelo implemento das universidades de ensino ou neoprofissionais em detrimento das universidades de pesquisa.

Talvez a forma mais visível de demonstrar que as teses disseminadas pelos organismos financeiros multilaterais tiveram claras conseqüências em diferentes países do mundo seja a exposição de dados que mostrem a redução dos investimentos estatais, do fundo público, na educação superior. No caso do Brasil, Nelson Cardoso Amaral, em sua obra Financiamento da educação superior: Estado x mercado (2003), expõe de forma exaustiva o quadro dos recursos financeiros aplicados pelo governo da União no sistema federal de educação superior no período 1989-2002. Para demonstrar a retirada do Estado da manutenção do Ensino Superior Público Federal, o autor estabelece a relação porcentual desses recursos com o PIB, com as despesas do Fundo Pú- 
blico Federal e com a arrecadação federal de impostos, como se pode ver na tabela a seguir.

Tabela 5.46 - Recursos das IFES como percentual do PIB, das Despesas Correntes do FPF e da arrecadação de impostos da União

Valores em R\$ milhões, a precos de janeiro de 2003 (IGP-DI/FGV)

\begin{tabular}{|c|c|c|c|c|c|c|c|}
\hline \multirow[t]{2}{*}{ Ano } & \multirow[t]{2}{*}{ PIB } & \multirow{2}{*}{$\begin{array}{c}\text { Despesas } \\
\text { Correntes } \\
\text { do FPF }\end{array}$} & \multirow[t]{2}{*}{ IMPOSTOS } & \multicolumn{4}{|c|}{ IFES } \\
\hline & & & & Recursos & $\%$ PIB & \%FPF & $\%$ Impostos \\
\hline 1989 & 1.408 .403 & 240.014 & 109.378 & 13.672 & 0,97 & 5,70 & 12,5 \\
\hline 1990 & 1.409 .181 & 229.929 & 119.886 & 11.133 & 0,79 & 4,84 & 9,3 \\
\hline 1991 & 1.432 .250 & 167.124 & 94.166 & 8.761 & 0,61 & 5,24 & 9,3 \\
\hline 1992 & 1.395 .684 & 184.753 & 56.889 & 7.921 & 0,57 & 4,29 & 13,9 \\
\hline 1993 & 1.393 .080 & 237.329 & 104.337 & 10.282 & 0,74 & 4,33 & 9,9 \\
\hline 1994 & 1.376 .560 & 229.352 & 139.352 & 12.504 & 0,91 & 5,45 & 9,0 \\
\hline 1995 & 1.521 .148 & 262.071 & 119.719 & 13.410 & 0,88 & 5,12 & 11,2 \\
\hline 1996 & 1.650 .403 & 270.722 & 119.806 & 12.084 & 0,73 & 4,46 & 10,1 \\
\hline 1997 & 1.709 .762 & 277.633 & 122.698 & 11.871 & 0,69 & 4,28 & 9,7 \\
\hline 1998 & 1.727 .901 & 305.880 & 136.897 & 11.662 & 0,67 & 3,81 & 8,5 \\
\hline 1999 & 1.653 .497 & 316.517 & 137.663 & 11.415 & 0,69 & 3,61 & 8,3 \\
\hline 2000 & 1.643 .493 & 296.127 & 125.560 & 10.760 & 0,65 & 3,63 & 8,6 \\
\hline 2001 & 1.622 .804 & 316.275 & 131.517 & 9.847 & 0,61 & 3,11 & 7,5 \\
\hline 2002 & 1.574 .396 & 316.320 & 126.473 & 10.012 & 0,64 & 3,17 & 7,9 \\
\hline
\end{tabular}

Fonte:PIB:Banco Central do Brasil e IPEA - http://www.ipeadata.gov.br; Impostos: Arrecadação da Receita Administrada pela SRF. http://www.receita.fazenda.gov.br; Recursos das IFES: 1990-1994:MF/STN/CGC; 19952002:Execução Orçamentária da União - http://www.camara.gov.br Desp. Correntes do FPF: Execução Orçamentária do Governo Federal e Balanço Geral da União.

(Amaral, 2003, p. 188)

Observe-se que os recursos destinados às IFES, que, em 1989 (Governo Sarney), correspondiam a 0,97\% do PIB, e que, em 1994 (Governo Itamar Franco), correspondiam a 0,91\%, caem gradativamente e, em 2001 , atingem apenas $0,61 \%$ desse indicador da riqueza nacional, isto é, uma queda de $34 \%$ no período. Com relação ao total de impostos arrecadados pela União a queda foi de $37 \%$ e com relação às despesas correntes do Fundo Público Federal a queda foi ainda mais acentuada: 44\%. Apresenta-se com toda a evidência, nesse período de 14 anos, a mais drástica redução dos recursos financeiros públicos aplicados às IFES nas últimas quatro ou cinco décadas.

Ocorre registrar que, ao passo que nesse período houve uma expansão de matrículas no ensino superior federal de 63\%, isto é, de 315 mil em 1989 para 522 mil em 2002, no ensino superior privado a ex- 
pansão foi de $160 \%$, isto é, as matrículas passaram de $934 \mathrm{mil}$ em 1989 para 2 milhões e 400 mil em 2002. No período 1994-2002, a expansão foi de $37 \%$ nas matrículas no ensino superior federal (a das IES privadas foi de $112 \%$ ), contra uma redução de $5 \%$ de seu corpo docente e de $21 \%$ de seu quadro de funcionários, além do quase congelamento salarial dos docentes e funcionários técnico-administrativos; este apenas tendo sido parcialmente compensado por uma gratificação proporcional aos índices individuais de "produtividade", intitulada, no caso dos docentes, de Gratificação de Estímulo à Docência (GED).

O custo/aluno, um dos principais alvos da crítica ao ensino superior federal, excluídos os gastos com hospitais universitários e outros não relacionados diretamente ao ensino, sofreu no período 1995-2001 uma redução de $51 \%$ (de $R \$ 11.198,00$ para $R \$ 5.488,00$ ). Este porcentual de redução, com valores a preços de janeiro de 2002 (IGP-DI/FGV), como fração do PIB nacional, foi de 53,7\% (Amaral, 2004, p. 123).

No período 1995-2002, envidaram-se muitos esforços oficiais para implantação de um tipo de autonomia - autonomia financeira, por oposição a autonomia de gestão financeira, constitucional - que objetivava conceder às IFES todas as prerrogativas e condiçôes para arrecadar fundos de qualquer natureza, na ausência do financiamento estatal previsto na Constituição. Como parte dessa política de desobrigação do Estado com relação à manutenção da educação superior, criaram-se todas as facilidades para a implantação de centenas de fundações de apoio institucional (FAI), entidades privadas, no interior dos campi universitários. ${ }^{17}$

É oportuno também observar que essa política de educação superior federal se desenvolveu quando o país possuía apenas entre 7\% e 9\% da faixa etária da população de 18 a 24 anos (entre as taxas mais baixas da América Latina) freqüentando algum dos cursos das 1.800 instituições de ensino superior no país, das quais apenas 160 universidades e dois terços delas privadas, e destas quase metade com fins lucrativos. ${ }^{18}$

\section{Considerações finais}

Tornado refém do sistema financeiro, o Estado nacional deixou de cumprir funções estruturantes essenciais.

(César Benjamim, 2004)

O dilema que enfrenta a universidade estatal pública, no Brasil - ser pensada oficialmente e atuar como bem público ou privado/ 
mercantil -, não é uma especificidade da universidade neste país. Esse dilema está sendo enfrentado nas últimas décadas por esta instituição nos países centrais e da periferia e semiperiferia, onde quer que os ventos ou as tempestades neoliberais, na economia e na reforma do Estado, fizeram-se presentes.

Jamais como hoje a universidade foi pensada como parte da economia. Jamais como hoje o conhecimento, a ciência e a tecnologia foram tão valorizados como mercadoria capital a ser apropriada hegemonicamente pelas grandes corporações globalizadas e no interesse dos países centrais. Se o diagnóstico neoliberal aponta a falta de competitividade como a grande fragilidade da economia, na crise do Estado do Bem-Estar, é essa característica-chave da empresa econômica e do mercado que, aos poucos, vai se implantando na universidade e tornando-se constitutiva de sua identidade. A idéia de uma universidade organizada e gerida nos moldes empresariais, trabalhando com uma semimercadoria no quasemercado educacional está cada vez mais presente no discurso e nas práticas oficiais das políticas públicas de educação superior.

É a partir disso e da consideração do papel das teses e recomendaçôes acima expostas que hoje podem ser mais bem identificados alguns traços fundamentais do "modelo de universidade mundial" que está em processo de implantação em diferentes países, isto é, uma universidade neoprofissional, heterônoma, operacional e empresarial/ competitiva.

A esse modelo alguns já denominaram de "universidade mundial do Banco Mundial" (Aboites, 1996), outros, de "modelo anglosaxão" - Inglaterra, Estados Unidos, Austrália, Nova Zelândia (Dias, 2003a). O fato é que, diante da predominância das teses do menor retorno individual e social dos investimentos na educação superior, comparativamente com o dos investimentos na educação básica, e do ensino superior como bem privado, diante das pressóes "públicas" e privadas por eficiência, competitividade etc., verifica-se a acentuação acelerada de um modelo de universidade, no Brasil, neoprofissional, em detrimento da universidade de pesquisa, cada vez mais restrita a um ínfimo número de instituições, que, com apoio do fundo público, têm consolidado a pós-graduação.

$\mathrm{O}$ processo de passagem de uma universidade autônoma para uma universidade heterônoma, como tem demonstrado Daniel Schugurenski a propósito do que viria ocorrendo no Canadá e alhures (2002), adquire, 
no caso do Brasil, características singulares, porque, com exceção das universidades estaduais paulistas, as universidades públicas (federais, municipais) jamais gozaram de efetiva autonomia, em especial administrativa e de gestão financeira. A "autonomia financeira" que nos últimos anos se pretendeu conceder às IFES, somada aos constrangimentos da falta de recursos e à diversificação de fontes de financiamento, via FAIs, e outros mecanismos, transformariam uma universidade sem autonomia numa universidade na qual setores externos, estatais ou do mercado, com seus interesses e sua lógica, teriam cada vez maior poder de definir a agenda universitária, no âmbito da administração, do ensino, da pesquisa e da extensão.

Esse traço da "nova" universidade se articula e se integra com os demais traços anteriormente apontados de uma universidade operacional e empresarial/competitiva, como muitos autores já o demonstraram (Chaui, 1999; Meek, 2002; Mollis, 2002; Sguissardi, 2004a e 2004b).

Concluindo: a questão-chave para se pensar a proteção e defesa da universidade pública é enfrentar o debate em torno do conhecimento, da ciência, da educação em geral e da educação superior em particular, como bem público $\mathrm{X}$ bem privado, ou, em outros termos, restabelecer o confronto entre o público e o privado/mercantil e tirar desse debate e desse confronto todas as conseqüências possíveis. É identificar os condicionantes históricos, político-econômicos, passados e presentes, que tornaram esse debate tão atual. É perceber, como diz César Benjamim, que o Estado Nacional, tornado refém do sistema financeiro, das "obrigações" assumidas com organismos multilaterais, num país campeão mundial de desigualdades, deixou de cumprir funções estruturantes essenciais, entre elas a de garantir a manutenção, a expansão e a qualidade de sua universidade pública.

Como pensar um país soberano e uma nação plenamente democrática, se os bens públicos universais são vistos como mercadorias ou semimercadorias e a universidade pública é cada vez mais identificada pela ótica empresarial competitiva?

Recebido e aprovado em abril de 2005.

\section{Notas}

1. "Um caso exemplar é o do Distrito Federal (DF, Brasília), que conta com 40 IES, mas com uma única pública (a UNB) e 39 privadas, das quais 37 particulares ou privadas stricto 
sensu. No DF, as vagas oferecidas foram, em 2000, 32.251, das quais apenas 3.904 (12\%) públicas e 28.347 (88\%) privadas: 3.910 (14\%) de IES comunitárias e/ou confessionais e 24.437 (86\%) de IES particulares ou privadas stricto sensu" (Sguissardi, 2002, p. 7).

2. Acrescentem-se os recursos públicos, via sistema de bolsas e outras formas de auxílio aos programas de pós-graduação das universidades privadas, garantidos por agências financiadoras oficiais (CAPES, CNPQ, FAPS etc.).

3. Sobre as teorias do "capital humano" e do "capital social", ver a tese, recentemente defendida por Valdemir Pires, intitulada Economia da educação e política educacional: elos fortes, consistência fraca (2003).

4. Veja-se o significado da presença, nessa obra clássica de economia política, de um capítulo sobre a educação, contemporâneo da Revolução Americana e precursor das famosas proposições para a legislação educacional da Constituinte da Revolução Francesa, em que se destacam peças como o Rapport Condorcet.

5. Ver de: 1) Joseph E. Stiglitz, Knowledge as a global public good, 1999; 2) Inge Kaul, Public/privé, Le Monde Diplomatique, junho 2000; 3) José C. Cavalcanti, "Educação superior: bem público ou privado?", JC e-mail, n. 2526, de 18 de maio de 2004, e JC email, n. 2572, de 19 de maio de 2004 (neste, sob enfoque economicista neoclássico, trata-se da educação superior como se fora uma mercadoria ou commodity típica do mercado das trocas mercantis, submetendo-a, de forma estreita, ao teste das propriedades de rivalidade e excluibilidade).

6. O fundo público é formado pelo conjunto de impostos, contribuições e taxas em cada instância estatal: federal, estadual ou municipal. Financia a burocracia do Estado e suas atividades no campo social e econômico.

7. Segundo Stiglitz (1999, nota 3), o conceito de conhecimento como bem público vem sendo articulado ao longo dos últimos 50 anos, desde a definição de bem público por Samuelson, em 1954 ("The pure theory of public expenditure", Review of Economics and Statistics, n. 36, p. 387-89), passando por Arrow, em 1962 ("The implications of learning by doing", Review of Economic Studies, n. 29, p. 155-173), Stiglitz, em 1977 ("Theory of local public goods", em The economics of public services, de M.S. Feldstein e R.P. Inman (Ed.), MacMillan Publishing Company, 1977, p. 274-333 [paper presented to IEA Conference, Turin, 1974]), Romer, em 1986 ("Increasing returns and long-run growth", Journal of Political Economy, 94:5, p. 1.002-1.037), Stiglitz, em 1995 ("The theory of international public goods and the architecture of international organizations", United Nations Background Paper, n. 7, Department for Economic and Social Information and Policy Analysis, July), e Economic Report of the President, em 1997 (Washington, United States Government Printing Office).

8. A autoria é atribuída a Georg Psacharopoulos, Jee-Peng Tan e Emmanuel Jimenez, com a colaboração de diversos consultores (ver créditos do documento).

9. Umas das performances comemoradas com relação ao Chile é a redução dos dispêndios estatais com a educação superior: "No mesmo período, a parte do gasto público destinada à educação superior, como porcentagem do PIB, diminuiu de 1,65 a 0,45\%" (WB, 1994, p. 33).

10. Na página 63 desse documento, declara-se: "No entanto, na maioria dos países em desenvolvimento, o grau de participação do governo no ensino pós-secundário ultrapassou em muito o que é economicamente eficiente".

11. Sua autoria é atribuída a D. Bruce Johnstone (da Universidade de Buffalo) com a colaboração de Alka Arora e William Experton.

Educ. Soc., Campinas, vol. 26, n. 90, p. 191-222, Jan./Abr. 2005

Disponível em <http://www.cedes.unicamp.br> 
12. John Barnes e Nicholas Barr (1988), Strategies for higher education: the alternative white paper, The David Hume Institute, The Suntory-Toyota International Center for Economics and related Disciplines, LSE, Aberdeen University Press, p. 3, 6-9 (nota 5 do documento do Banco).

13. Ver nota 6, acima.

14. Cf., de Marco Antonio R. Dias (2003c), "Comercialização no ensino superior: é possível manter a idéia de bem público?” Educação \& Sociedade, n. 84; de Jane Knight (2002) "Trade in higher education services: the implications of GATS", Londres, Observatory on Borderless Higher Education; disponível em: <http://www.obhe.ac.uk>.

15. Retomam-se aqui, essencialmente, os comentários feitos pelo Comitê Editorial da Revista Educação \& Sociedade, no editorial "Educação: de direito de cidadania a mercadoria", de seu n. 84, de setembro de 2003.

16. Cf. de Roberto Rodríguez Gómez, "La educación superior transnacional en México - El caso Sylvan-Universidad del Valle de México", Educação \& Sociedade, Campinas, v. 25, n. 88, p. 1.044-1.068 - edição especial, e sua extensa bibliografia a respeito do tema.

17. No ano de 2001 as FAI's eram 96 nas IFES, com um crescimento de $129 \%$ em relação ao ano de 1995 (Amaral, 2003, p. 183). Sobre as mais de 30 FAI's da USP, cf. em especial o Dossiê "Fundaçôes" dos números 22, 23 e 24 da Revista da ADUSP, de março, setembro e dezembro de 2001, respectivamente. Em edição especial da Folha de S. Paulo (São Paulo, quarta-feira, 5 de maio de 2004), informa-se que as FAI's da usp teriam arrecadado, no ano de 2001, R\$ 457,8 milhões (orçamento da USP nesse ano: R \$ 1 bilhão e 273 milhões) e repassado à USP $\mathrm{R}$ \$ 19,5 milhōes ou apenas 4,26\% do total arrecadado. Informa-se ainda que 55 docentes da Fundação Instituto de Administração (FIA), ligada à Faculdade de Economia e Administração (FEA), tiveram uma remuneração média mensal de $\mathrm{R} \$ 32,5$ mil, excluído o salário da USP, que, para um docente doutor, vai de $\mathrm{R} \$ 4.700,00$ a 7.400,00 por mês.

18. Sobre a forma como se vão constituindo as IES privadas com fins lucrativos, diz Boaventura de S. Santos (2004, p. 107): "O modo como se constituiu este sector privado de ensino superior diverge de país para país. Mas nos países periféricos e semiperiféricos, em que havia um sector público universitário, o desenvolvimento do sector privado lucrativo assentou em três decisões políticas: estancar a expansão do sector público através da crise financeira; degradar os salários dos professores universitários a fim de os forçar a buscar emprego parcial no sector privado (no caso do Brasil, outro factor foi permitir a aposentadoria precoce, com salário integral, das universidades públicas); actuar com uma negligência benigna e premeditada na regulação do sector privado, permitindo-lhe que ele se desenvolvesse com um mínimo de constrangimentos. Desse modo, o sector privado foi dispensado de formar os seus próprios quadros e aproveitar-se de todo o conhecimento e formação produzidos na universidade pública. Isso significou uma maciça transferência de recursos da universidade pública para as novas universidades privadas, uma transferência de tal montante e tão selvagem que é legítimo concebê-la como um processo de acumulação primitiva por parte do capital universitário com a conseqüente descapitalização e desarticulação da universidade pública".

\title{
Referências bibliográficas
}

\begin{abstract}
ABOITES, H. Banco Mundial y universidad: el fin de la autonomia, el comienzo del cogobierno; ponencia presentada en Reunión de Análisis
\end{abstract}

Educ. Soc., Campinas, vol. 26, n. 90, p. 191-222, Jan./Abr. 2005

Disponível em <http://www.cedes.unicamp.br> 
de las Ciencias, la Educación y la Cultura, Cuernavaca, Morelos, MX, 13 jul. 1996. Disponível em: <http://www.smf.mx/boletin/Jul-96/ articles/banco.html $>$. Acesso em: 10 ago. 1996.

AMARAL, N.C. Financiamento da educação superior: Estado x mercado. São Paulo: Cortez; Piracicaba: Unimep, 2003.

AMARAL, N.C. Evolução do custo do aluno das IFes: eficiência? Avaliação, Campinas, v. 9, n. 2, p. 115-126, jan. 2004.

APPLE, M. Educando à direita: mercado, padrōes, Deus e desigualdade. São Paulo: Cortez; IPF, 2003a.

APPLE, M. Aliança estratégica ou estratégia hegemônica? Conservadorismo entre os desfavorecidos. Educação \& Sociedade, Campinas, v. 24, n. 84, p. 1019-1042, set. 2003b.

BARR, N. The economics of the Welfare State. 2. ed. London: Weidenfeld and Nicholson, 1993

BENJAMIM, C. Vôo cego. Caros Amigos, São Paulo, n. 86, maio 2004.

BOURDIEU, P. A mão esquerda e a mão direita do Estado. In: BourDIEU, P. Contrafogos: táticas para enfrentar a invasão neoliberal. Rio de Janeiro: Jorge Zahar, 1998. p. 9-21.

BOURDIEU, P.; WACQUANT, L. La nouvelle vulgate planétaire. Le Monde Diplomatique, Paris, maio 2000.

BRASIL. Ministério da Administração Federal e da Reforma do Estado. Plano Diretor da Reforma do Estado. Brasília, DF: MARE, 1995.

CAMARGO, E.A.S.P. et al. Educação: de direito de cidadania a mercadoria. Educação \& Sociedade, Campinas, v. 24, n. 84, p. 727-731, set. 2003.

CAVALCANTI, J. C. Educação superior: bem público ou privado? JC email, n. 2526, de 18 de maio de 2004, e JC e-mail, n. 2572, de 19 de maio de 2004.

CHAUI, M. A universidade operacional. Folha de S. Paulo, São Paulo, 9 maio 1999. Caderno Mais! Brasil 500 D.C., p. 3.

DIAS, M.A.R. Mudança e desenvolvimento no ensino superior. In.: TRINDADE, H.; LuCE, M.B. (Org.). Mudança e desenvolvimento da universidade 
pública na América Latina; anais do Seminário Internacional da ANDIFES, 1995, Brasília, DF. Brasília, DF: ANDifes, 1996. p. 23-35.

DIAS, M.A.R. Produção, partilha e apropriação do conhecimento. In: SEMINARIO Internacional Universidade XXI, nov. 2003, Brasilia, DF. Brasilia, DF, 2003a.

DIAS, M.A.R. Espacios solidarios en tiempos de oscurantismo; inauguración oficial del año académico 2003-2004 del conjunto de las universidades de Catalunya, Universidad Politécnica de Catalunya, 25 sept. 2003b. Disponível em: <http://www.crue.org/espaiberodoc/ Lliçoinaugural_barcelona2003.pdf>. Acesso em: 27 jul. 2004.

DIAS, M.A.R. Comercialização no ensino superior: é possível manter a idéia de bem público? Educação \& Sociedade, Campinas, v. 24, n. 84, p. 817-838, set. 2003c.

DREIFUSS, R.A. 1964: a conquista do Estado; ação política, poder e golpe de classe. Petrópolis: Vozes, 1981.

JOHNSTONE, D.B. et al. The financing and management of higher education: a status report on worldwide reforms. Washington, DC: World Bank, 1998.

KAUL, I. Public/privé. Le Monde Diplomatique, Paris, p.22, jun. 2000. Disponível em: <http://www.monde-diplomatique.fr/2000/ 06/KAUL/13928>. Acesso em: 24 jul. 2004.

MANACORDA, M.A. Marx y la pedagogía de nuestro tiempo. Guerrero, Mx: Unión Sindical de Professores de la Universidad Autónoma de Gerrero, s.d.

MARX, K. Crítica ao Programa de Gota: observações à margem do Programa do Partido Operário Alemão. In: MARX, K.; Engels, F. Obras escolhidas. São Paulo: Alfa-Omega, s.d. p. 209-225.

MEEK, V.L. Use of the "market" in the transformation of Australian higher education. In: Rodriguez Gómez, R. (Org.). Reformas en los sistemas nacionales de educación superior. La Coruña: Netbiblo, 2002. p. $149-178$.

MOLLIS, M. La geopolítica de las reformas de la educación superior: el Norte da créditos, el Sur se "acredita". In: Rodriguez Gómez, 
R. (Org.). Reformas en los sistemas nacionales de educación superior. La Coruña: Netbiblo, 2002. p. 321-358.

PIRES, V. Economia da educação e política educacional: elos fortes, consistência fraca. 2003. Tese (Doutorado) - Programa de Pós-Graduação em Educação, Universidade Metodista de Piracicaba (UNIMEP), Piracicaba.

O BUSINESS e a educação; especialista defende a gestão das escolas como um negócio e com foco nos resultados. Revista do Ensino Superior, São Paulo, v. 6, n. 68, p. 22, maio 2004.

SADER, E. Público versus mercantil. Folha de S. Paulo, São Paulo, 19 jun. 2003, p. 3

SAINT-PIERRE, C. Discurso no encerramento da Conferência Mundial sobre o Ensino Superior. In: UNESCO; CRUB; CAPES. Tendências da Educação Superior para o Século XXI; anais da Conferência Mundial sobre o Ensino Superior, 5 a 9 out 1998, Paris. p. 77-86.

SANTOS, B.S. A universidade do século XXI: para uma reforma democrática e emancipatória da universidade. São Paulo: Cortez, 2004. (Questôes da nossa época, v. 120)

SCHUGURENSKY, D. Autonomía, heteronomía, y los dilemas de la educación superior en la transición al siglo XXI: el caso de Canadá. In: Rodriguez Gómez, R. (Org.). Reformas en los sistemas nacionales de educación superior. La Coruña: Netbiblo, 2002. p. 109-148.

SGUISSARDI, V. O Banco Mundial e a educação superior: revisando teses e posiçôes? Universidade e Sociedade, Brasília, DF, v. 10, n. 22, p. 66-77, 2000.

SGUISSARDI, V. Privatização da educação superior no Brasil: 19952001. Revista de la Educación Superior, México, v. 31, n. 123, jul./ sept. 2002.

SGUISSARDI, V. Educação superior no limiar do novo século: traços internacionais e marcas domésticas. In: ZainKo, M.A.S.; Gisi, M.L. (Org.). Políticas e gestão da educação superior. Curitiba: Champagnat; Florianópolis: Insular, 2003. p. 195-222. 
SGUISSARDI, V. Universidade neoprofissional, heterônoma e competitiva. In: FÁvero, M.L.; Mancebo, D. (Org.). Universidade: políticas, avaliação e trabalho docente. São Paulo: Cortez, 2004a. (no prelo)

SGUISSARDI, V. Rumo à universidade mundial: e a universidade será feita a sua imagem e semelhança. Brasília: DF, INEP/MEC, 2004 b.

SMITH, A. Riqueza das nações. Lisboa: Fundação Calouste Gulbenkian, 1983. v.2.

STIGLITZ, J. Knowledge as a global public good. In: KaUL, I.; Grunberg, I.; Stern, M. A. (Org.). Global public goods: international co-operation in the 21 st century. New York: Oxford University, 1999.

STIGLITZ, J. Knowledge as a global public good. Washington, DC: World Bank, 1999. Disponível em: <http://www.worldbank.org/ knowledge/chiefecon/articles/undpk2/w2wtoc.htm>. Acesso em: 24 jul. 2004.

UNESCO. Vers un Agenda 21 pour l'enseignement supérieur: défis et tâches dans la perspective du XXIe siècle à la lumière des conférences regionales. In: Conférence Mondiale sur l'Enseignement Supérieur. L'Enseignement Supérieur au XXIe Siècle : visions et actions, 5-9 octobre 1998, Paris.

UNESCO. Conférence Mondiale sur l'Enseignement Supérieur. Déclaration Mondiale sur l'Enseignement Supérieur du XXIe Siècle: vision et action, 5-9 octobre 1998, Paris.

WORLD BANK. Financing education in developing countries: an exploration of policy options. Washington, DC: World Bank, 1986.

WORLD BANK. Higher education: the lessons of experience. Washington, DC: World Bank, 1994.

WORLD BANK. Task Force on Higher Education and Society. Higher education in developing countries: peril and promise. Washington, DC: World Bank, 2000. Disponível em: <http://www.tfhe.net>. Acesso em: 20 jul. 2004. 